\title{
Educação Permanente em Saúde no Brasil: educação ou gerenciamento permanente?
}

\author{
Ongoing Health Education in Brazil: \\ education or ongoing management?
}

Cristiane Lopes Simão Lemos ${ }^{1}$

${ }^{1}$ Instituto de Ciências Biológicas, Universidade Federal de Goiás. Campus Samambaia. 74001-970 Goiania GO Brasil. professoracristi@gmail.com

\begin{abstract}
The scope of this study was to analyze the concept and principles of Ongoing Health Education (OHE) - the Brazilian acronym is PNEPS. The methodology was based on the anal$y$ sis of documents from the Ministry of Health and related scientific articles. It was revealed that the concept of OHE transcends its pedagogical significance and is undergoing a service restructuring process in the face of the new demands of the model. Precisely at the time in which jobs are increasingly unstable and precarious, the Ministry of Health engages in discourse regarding innovative management, focusing on the issue of OHE. The idea is not one of ongoing education, but of ongoing management. Rather than being an instrument for radical transformation, OHE becomes an attractive ideology due to its appearance as a pedagogical novelty.
\end{abstract}

Key words Education in health, Human resources in healthcare, Healthcare policies
Resumo O objetivo do estudo foi analisar a concepção e os fundamentos da Educação Permanente em Saúde (EPS) constante da Politica Nacional de Educação Permanente em Saúde (PNEPS) no Brasil. A metodologia baseou-se na análise de documentos do Ministério da Saúde e de artigos científicos relacionados. Constatou-se que a concepção da EPS na PNEPS transcende um significado pedagógico, respondendo a um processo de reestruturação dos serviços diante das novas demandas do modelo. Justamente no momento em que o trabalho se encontra cada vez mais instável e precarizado, o Ministério da Saúde apresenta um discurso sobre uma gestão inovadora, dando centralidade à questão da EPS. A ideia não é de educação permanente, mas de gerenciamento permanente. Ao contrário de um instrumento de transformação radical, a EPS converte-se em uma ideologia que seduz pela sua aparência de novidade pedagógica.

Palavras-chave Educação em saúde, Recursos humanos em saúde, Políticas de saúde 


\section{Introdução}

O termo educação permanente aparece pela primeira vez na França em 1955 e foi oficializado no ano seguinte em um documento do Ministro Educacional sobre o prolongamento da escolaridade obrigatória e a reforma do ensino público ${ }^{1}$. No final da década de 1960, passa a ser difundida pela UNESCO, fundamentada na teoria do capital humano ${ }^{2}$, que compreende a qualificação do fator humano como um dos mais importantes meios para a produtividade econômica e o desenvolvimento do país. Paiva ${ }^{3}$ analisa a produção teórica e o contexto de implantação da educação permanente no país neste período e a compreende como uma ferramenta ideológica do Estado para inculcar nos trabalhadores novas formas de trabalho com centralidade às necessidades do capitalismo tardio.

A denominada Educação Permanente em Saúde (EPS) surge em meados da década de 1980, tendo sido disseminada pelo Programa de Desenvolvimento de Recursos Humanos da Organização Pan Americana de Saúde (OPAS) ${ }^{4,5}$.

A OPAS cria uma diferenciação entre os termos educação permanente e educação continua$\mathrm{da}$, considerando a última mais reducionista. No entanto, esta distinção não tem unanimidade no meio acadêmico. Em total oposição ao conceito da OPAS, Marin ${ }^{6}$ entende que educação continuada seria mais completa por incorporar a ideia de formação no próprio local de trabalho, sem interrupção ou fragmentação, dependendo dos objetivos que se quer alcançar. De outro modo Haddad et al. ${ }^{7}$, admite que a educação permanente inclui a educação continuada e a educação em serviço. Ramos ${ }^{8}$ assevera que, em um contexto mais amplo, educação continuada, educação permanente, aprendizagem ao longo da vida, educação de adultos podem ser considerados sinônimos.

Vieira et al. ${ }^{9}$ consideram que para além das controvérsias da nomenclatura a EPS começa a ser estruturada pela OPAS, em virtude da necessidade de utilizar um "novo vocábulo" para implantar as mudanças que o setor enfrentaria perante as novas demandas da reestruturação do capital.

É importante ressaltar que a década de 1980 tem como pano de fundo a queda do muro de Berlim, o fortalecimento do neoliberalismo, os questionamentos sobre o socialismo e as teses pós-modernas de "fim" da história, além do desmoronamento da união do "fordismo/taylorismo e do keynesianismo". Todas estas mudanças repercutem na educação dos trabalhadores e é neste contexto que a ideia da Educação Permanente em Saúde é concebida pela OPAS, pois:

Se requiere una revisión conceptual y metodológica y la creación y adaptación de instrumentos distintos de los utilizados hasta hoy, porque son situaciones con otro ritmo, otra intensidad, otros requisitos y en consecuencia, otros fine. [...] se hace necesario promover estudios e y desarrollar procedimientos que posibiliten una utilización más racional del personal existente asegurando la educación permanente de los recursos humanos ya incorporados a la fuerza de trabajo sectoral ${ }^{5}$.

Lemos $^{10}$ compreende que as situações com outro ritmo, outra intensidade, outros requisitos estão ligadas à implantação do novo modelo de reestruturação produtiva do capital. Baseada no modelo de produção toyotista, a intenção da OPAS foi construir um novo referencial pedagógico, a "educação permanente", no qual o trabalhador tenha maior envolvimento no processo produtivo da saúde, superando o "trabajo actual (fragmentado, deshumanizado, conflictivo, alienante por efectos de la lógica tayloriana imperante), [...] orientadas a la mejoría de la calidad" (grifos nossos).

Assim percebe-se que a origem da EPS tem relação com a incorporação do modelo empresarial toyotista no mundo do trabalho da saúde, pois o taylorismo/fordismo passa a significar uma rigidez que não responde rapidamente às problemáticas que se apresentam, colocando em cheque toda a base do capital sustentado durante décadas. Ao contrário do fordismo, que, de certa forma, minimiza a dimensão intelectual do trabalho, com a produção de atividades repetitivas e desprovidas de sentidos, o modelo toyotista cria uma lógica mais integrativa do operariado na organização do trabalho.

No Brasil, com o SUS e os novos desafios assumidos, a formação dos trabalhadores da saúde passa a ter maior ênfase. No texto da Constituição Federal (Artigo 200), fica estabelecido que "ao sistema único de saúde compete, além de outras atribuições, nos termos da lei, ordenar a formação de recursos humanos na área da saúde"12. A formação profissional passou a ser reconhecida como fator essencial para o processo de consolidação da Reforma Sanitária Brasileira ${ }^{13}$. Somente em 2003 é criada, no Ministério da Saúde, a Secretaria de Gestão de Trabalho e da Educação em Saúde (SGTES), que assumiu a responsabilidade de formular políticas orientadoras da gestão, formação, qualificação e regulação dos trabalhadores da saúde no Brasil. 
Em 2004, foi implantada a Política Nacional de Educação Permanente em Saúde (PNEPS) pela Portaria $198^{14}$ qual o Ministério da Saúde assume a responsabilidade constitucional de ordenar a formação seus recursos humanos.

Com a PNEPS criou-se Polos de Educação Permanente em Saúde (PEPS) que foram eficazes na difusão da proposta da EPS pelos diferentes municípios brasileiros. É importante situar que no ano de 2005 houve troca do ministro da saúde, e alterações no quadro de trabalhadores e gestores SGTES e em agosto de 2007, a PNEPS foi alterada pela Portaria GM/MS no $1996^{15}$. Com isso inicia a segunda fase da PNEPS (que não será analisada neste estudo) com mudanças conceituais e metodológicas em relação à condução da PNEPS. As Comissões Integração Ensino Serviço (CIES) e os Colegiados de Gestão substituem os PEPS na gestão da EPS.

Foi na vivência no PEPS de Goiânia no período de 2003 a 2004 e nas leituras dos documentos acerca da PNEPS que surgiu o interesse em investigar a EPS. O primeiro contato com a proposta da EPS trouxe grande entusiasmo para quem sonha com uma educação transformadora na saúde. A preconização de uma educação permanente vinculada a uma política ministerial deu peso ao nosso interesse em estudar esta temática. O ingresso no Doutorado em Educação da Universidade Federal de Goiás (UFG) permitiu um aprofundamento teórico sobre o tema e uma ampliação do olhar sobre questões epistemológicas, ontológicas e filosóficas sobre educação e trabalho.

Dos embates teóricos e práticos, surgiu uma questão central: Qual é a concepção de educação da Política Nacional de Educação Permanente em Saúde? Nessa perspectiva o presente estudo teve como objetivo a analisar os referenciais da Educação Permanente em Saúde (EPS) constante na primeira fase da PNEPS no período de 2003 a 2005.

\section{Metodologia}

A metodologia baseou-se na análise de documentos do Ministério da Saúde relativos à primeira fase da PNEPS (2003-2005). Foram investigados os documentos ${ }^{14,16-19}$. Também foram utilizadas as publicações dos gestores/consultor do Departamento de Gestão e Educação na Saúde (DEGES) que estiveram envolvidos na implementação da PNEPS neste período. Destaca-se a produção de Ceccim ${ }^{20,21}$, Merhy ${ }^{22}$, Ceccim e Feue- rwerker ${ }^{23}$, Merhy et al. ${ }^{24}$, autores/gestores que, de 2003 a 2005, participaram da implantação e condução da PNEPS.

O cruzamento das informações dos documentos legais com as ideias sustentadas nos artigos relativos à PNEPS foi primordial para uma maior aproximação do objeto de estudo aqui proposto. Em síntese, foram realizadas as seguintes etapas metodológicas:

(1) catalogação dos documentos Ministério da Saúde relativos à primeira fase da PNEPS (2003 -2005)

(2) seleção de textos de autores envolvidos com a implantação da PNEPS neste período,

(3) leitura e investigação dos documentos e artigos;

(4) organização dos dados, construção e análise das categorias.

O referencial teórico do estudo apoiou-se nas contribuições de autores que se aproximam do enfoque marxista de educação e trabalho. A opção por este referencial teórico também reitera a importância da retomada do marxismo para refletir acerca dos objetos da saúde coletiva ${ }^{25}$.

\section{Resultados}

Com implantação da PNEPS pela Portaria no 198/GM/MS de 13 de fevereiro de $2004^{14}$ a EPS passa a ser amplamente difundida. Na visão da SGTES os cursos tradicionais focados na proposta da educação continuada não são suficientes, pois "Capacitam-se profissionais" que "ao retornarem aos seus serviços não conseguem 'aplicar' o que 'aprenderam' ou constatam que o que 'aprenderam' não lhes fornece elementos suficientes para enfrentar as problemáticas da realidade concreta"16.

Pela análise dos documentos relacionados à PNEPS, percebe-se que a proposta ministerial é tributária de alguns referenciais da OPAS. A ideia da Educação Permanente como "aprendizagem no trabalho, onde o aprender e o ensinar se incorporam ao cotidiano das organizações e ao trabalho" ${ }^{5}$ sustentada pela OPAS também está presente na PNEPS. Também se adotam os referenciais construtivistas (problematização e aprendizagem significativa) da educação como possibilidade de transformação do SUS.

Contudo, é importante destacar que não houve uma transposição sistemática do ideário da EPS da OPAS para o Brasil ${ }^{10,26}$. Embora reconheçamos uma filiação da ideia do organismo internacional, percebemos que, no contexto 
brasileiro, houve novos contornos e desenhos na proposta que serão analisados a seguir.

Na primeira fase da PNEPS há um grande diferencial que é o referencial do quadrilátero da formação ${ }^{17}$, que amplia o âmbito da atuação da EPS da tradicional parceria ensino/serviço já previsto na OPAS para outros segmentos. A ideia é de retirar o planejamento dos órgãos centrais e promover uma gestão da educação descentralizada e de forma democrática pelos PEPs ou "Rodas de Gestão" compostos por diversos setores envolvendo, agora, na elaboração do planejamento da EPS: trabalhadores, gestores, usuários (controle social), professores/acadêmicos.

Sem a intenção de aprofundar nas diferenças entre OPAS e PNEPS, que fogem ao escopo deste trabalho e estão melhor analisadas nos estudos de Bravin ${ }^{26}$ e Lemos ${ }^{10}$, é possível constatar por meio da análise documental e de artigos relacionados à implantação da PNEPS (2003-2005) que o eixo central da proposta de EPS da PNEPS é o trabalho como fundamento educativo e transformador da realidade.

\section{Discussão}

A PNEPS tem o trabalho como elemento central e transformador da realidade. No entanto, a relação entre a educação e trabalho foi compreendida por Marx como uma relação dialética, podendo ser marcada por uma positividade ou negatividade, a depender do contexto histórico-social em que ela se desenvolve. Na perspectiva ontológica marxista, o trabalho é o elemento fundante de todas e quaisquer relações e constitui em elemento de transformação humana. Contudo, na particularidade histórica do capitalismo, o trabalho carrega em si uma negatividade. Ao invés de criação, torna-se alienação. O homem deixa de ser "homem", desumaniza-se ocorrendo um processo de "coisificação" da essência que vai repercutir nas suas relações sociais que se tornam embrutecidas e desumanizadas ${ }^{27}$.

Por meio da análise da PNEPS observa-se um constructo teórico que se opõe as ideias marxistas sobre a alienação do trabalho no sistema do capital. A PNEPS concebe uma positividade na relação entre educação e trabalho, ao considerar a "transformação das práticas profissionais e da própria organização do trabalho", o que contraria as teses marxistas que veem a impossibilidade do trabalho como fundamento educativo no capitalismo.

Assim com a criação da PNEPS, o trabalho toma uma grande centralidade:
No mundo do trabalho, a responsabilidade dos serviços de saúde no processo de transformação das práticas profissionais e das estratégias de organização da atenção à saúde, levou ao desenvolvimento da proposta da educação permanente, considerada um recurso estratégico para a gestão do trabalho e da educação na saúde $e^{16}$.

A possibilidade de transformação do trabalho do SUS na PNEPS ancora-se na EPS a partir três fundamentos centrais: a micropolítica do trabalho vivo, método da roda e problematização/aprendizagem significativa que iremos discutir em seguida. É importante entender que os três elementos estão entrelaçados e na lógica do DEGES possibilita educar um sujeito com compromisso e capacidade de gerar resolutividade aos problemas da saúde pública brasileira.

A micropolítica do trabalho vivo reconhece o mundo do trabalho como espaço de criação de novas subjetividades essenciais para a mudança institucional. Micropolítica é um termo utilizado por Guattari, que tem influência de Deleuze. Refere-se aos efeitos da subjetivação, conjunto de fenômenos e práticas capazes de ativar estados e alterar conceitos, percepções e afetos (modos de pensar-sentir- querer). "Toda problemática micropolítica consiste, exactamente, en intentar agenciar los procesos de singularización en el propio nivel en el cual emergen"28.

Na perspectiva da micropolítica, a educação deve ser um instrumento permanente, que estimule os trabalhadores a novas posturas para um melhor cuidado com a saúde. Segundo Merhy et al. ${ }^{24}$ :

En la política de educación para el SUS, la gestión del Ministerio de Salud entre 2003 y 2005, se propuso trabajar la EPS como una "caja de herramientas" que permitiera actuar sobre la micro-política del trabajo en salud, para ampliar los espacios locales de concertación de políticas y los espacios de libertad de los trabajadores en la conformación de las prácticas, y crear espacios colectivos con potencial para construir nuevos acuerdos de convivencia, comprometidos con los intereses y necesidades de los usuários.

$\mathrm{Na}$ visão destes autores, a ideia da formação como política do SUS poderia se inscrever como uma potência permanente para desencadear uma positividade nos trabalhadores para inventarem a mudança no serviço de saúde. A teoria da micropolítica tem como pressuposto que a organização do saber não se estrutura igualmente nos diferentes tipos de trabalho, havendo processos produtivos nos quais o peso que o trabalho morto expressa é maior que o trabalho vivo ou vice versa. Segundo a micropolítica, em certas produções, o processo 
de captura do trabalho vivo pelo trabalho morto é diferenciado, permitindo imaginar situações em que o exercício do protagonismo/liberdade predomine em relação aos momentos de protagonismo/reprodução no mundo geral da produção. Contrariamente, há uma aposta em um "trabalho vivo", baseado principalmente nas concepções acerca da "micropolítica do trabalho vivo".

É preciso explicitar que na micropolítica do trabalho vivo não se concebe a noção de trabalho discutida por Marx ${ }^{27,29}$. A ideia da micropolítica é trabalhada por Merhy ${ }^{30}$ na perspectiva da mudança institucional nos serviços de saúde. $\mathrm{O}$ autor $^{30}$ identifica na área da saúde a existência de uma "maleta tecnológica" com três tipos de tecnologias: duras, leve-duras e leves. As tecnologias duras estão relacionadas aos equipamentos tecnológicos do tipo máquinas, normas e estruturas organizacionais. As tecnologias leve-duras seriam as intermediárias, como, por exemplo: os saberes estruturados que operam no processo de trabalho em saúde. As tecnologias leves dizem respeito aos processos relacionais no encontro entre o trabalhador de saúde e o usuário.

A mudança de postura é fundamental para o trabalho vivo em ato e é aí que estratégia da EPS se articula, impelindo os trabalhadores a reduzir a dimensão centrada no profissional ou nos procedimentos (tecnologia leve-duras e duras) e enfatizar o eixo das tecnologias leves, levando os profissionais, quando do encontro com seus pacientes, a ser mais humanizados e ter maior compromisso com a ação de cuidar do usuário. "Lo que confiere vida al trabajo en salud son justamente las tecnologías "blandas", que posibilitan al trabajador actuar sobre las realidades singulares de cada usuario en cada contexto, utilizando las tecnologías "duras" y "blanda-duras" como una referencia ${ }^{24}$.

É no constructo teórico/prático das tecnologias leves é que a PNEPS compreende sua principal estratégia, tese reconhecida no estudo ${ }^{9}$. A micropolitica do trabalho vivo atribui ao trabalhador uma potência que lhe permitiria confrontar e superar a alienação do trabalho no sistema capitalista. Tudo estaria condicionado ao trabalhador da saúde adotar uma nova postura relacional, ter maior comprometimento e intencionalidade em estabelecer uma relação mais humanizada no atendimento e no trabalho de equipe, oferecer bem-estar aos usuários e em consequência tornar a sua atividade válida e reconhecida para ele mesmo.

Ao contrário do trabalho fabril, admite-se uma relação positiva entre educação e o traba- lho na saúde por ser relacional, na relação entre profissional e usuário. No entanto, Lukács ${ }^{31}$ partindo da tese da práxis interativa, compreende que o capital não deforma o sujeito apenas no seu trabalho propriamente dito, mas, de forma contínua e constante, vai se entremeando nas relações familiares, na escola, na igreja, em todos os espaços interativos que são determinados pela objetividade do sistema capitalista. Nesta mesma visão Mészáros ${ }^{32}$ considera que o capitalismo é estruturado de maneira mutuamente antagônica das menores células ou "microcosmos" que o constituem às mais abrangentes unidades globais de intercâmbio econômico e político e por isto, não se dá apenas no trabalho propriamente dito mas em todas as interações humanas e por isto se situa em uma "complexidade insuperável".

Esta complexidade é banalizada pela a $m i$ cropolítica do trabalho vivo ao dar grande peso à intencionalidade do sujeito na superação do capitalismo. Para Lucacks ${ }^{31}$ não se pode separar os atos relacionais dos processos de alienação do capital. O trabalhador da saúde não é um fragmento descolado da história e por isso sujeita-se e é sujeitado à lógica do capital. Constitui-se, assim, em meio a uma tensão entre subjetividade/ objetividade, que não é reconhecida na lógica da PNEPS.

Na visão de Vieira et al. ${ }^{9}$ há uma visão unilateral que os formuladores da PNEPS assumem ao não tratar a relação entre infraestrutura/superestrutura como uma totalidade, o que lhes permite afirmar a possibilidade da desalienação dos trabalhadores, pela constituição de uma nova subjetividade, desconsiderando a interferência da base material na constituição da subjetividade do trabalhador e na própria relação deste com o usuário.

É preciso entender que o trabalho da saúde não está inserido numa bolha imune aos problemas do capital. O trabalhador da saúde, como qualquer outro, está submetido à lógica do capital e o seu trabalho por mais relacional ou humanizado que seja também está voltado para a lógica mercantil de acumulação. A alienação não se dá apenas no ato da produção material (no cotidiano do trabalho), se constitui a partir do um estranhamento do trabalhador consigo e com os outros, intervindo nas relações e constituição do homem para si e para os outros homens ${ }^{33}$.

O estudo de Garrafa e Cordón ${ }^{34}$ reconhece que os espaços do cuidado profissional são inevitavelmente regulados pelo capital. $\mathrm{O}$ trabalhador da saúde também se vê impulsionado a atingir metas de produtividade, a ter seus serviços ava- 
liados permanentemente, a manter seus conhecimentos atualizados. Kuenzer ${ }^{35}$ assevera os trabalhadores deste setor não se diferenciam dos demais, no tocante a sua superexploração, em face da valorização do capital que o submete a mais sofrimento. $\mathrm{O}$ avanço da terceirização das instituições do SUS, a extinção dos concursos públicos e a criação de contratos seletivos que ampliam a precarização do trabalhado têm sido um dos sintomas mais recentes do avanço do neoliberalismo.

Ao valorizar a subjetividade, o cotidiano, a construção e desconstrução de territórios, a micropolitica do trabalho vivo coloca-se na lógica pós-moderna, chegando a considerar que nestes processos. "não há um sujeito, mas singularidades, algo parecido com a ideia de que 'um' são 'vários"'36. Nesse sentido, pode-se chegar à compreensão de que, ao invés de construção de autonomia, corre-se o risco de cair num relativismo, que dilui a história e mantém o capitalismo como sistema societal inquestionável, pois sem sujeitos históricos também não há razão para pensar a exploração do capital e os processos de luta para sua superação!

Eis uma contradição na micropolitica do trabalho vivo: efetuar uma reestruturação produtiva no trabalho do SUS em consonância com o interesse dos usuários, porém não antagônica aos interesses do capital. Sem sujeitos, sem história, de alguma forma há uma perda de sentido e também de luta pela saúde, fato favorável à consolidação do capital ${ }^{10}$.

Como acontece na tese da micropolítica do trabalho vivo, o método da roda valoriza a construção subjetiva da liberdade, ou seja, estruturase com base na possibilidade de expressão dos desejos, interesses e valores particulares ou singulares e se articula para a criação de espaços de diálogo e confrontos para manifestação destes. Contrapondo aos projetos tradicionais de gestão, organizados verticalmente por especialistas, buscou-se na PNEPS um método mais solidário, com interesses e valores diferentes e uso de convencimento e de negociação como instrumento ${ }^{37,38}$.

Com base na interação comunicacional como mecanismo para eliminar as supostas diferenças e hierarquia entre os ocupantes da roda, pauta-se por uma suposta igualdade de condições entre os componentes do quadrilátero para fazer reflexões e procurar soluções para os problemas da EPS.

Nessa relação entre ensino e sistema de saúde, sai a arquitetura do organograma para entrar a dinâmica da roda. A noção de gestão colegiada, como nas rodas dos jogos infantis, coloca a todos como participantes de uma operação conjunta em que todos usufruem o protagonismo e a produção coletiva $^{20}$.

A curta existência e as dificuldades de trabalho democrático nos $\mathrm{PEPS}^{26}$, todavia demonstram a tensão real da roda viva, pois o discurso da igualdade não suprime a desigualdade real que existe no período histórico do capital. Há de reconhecer que até mesmo nos jogos de crianças existem dificuldades de reconhecer o mesmo direito de voz.

Se não houver uma direção política para uma mudança efetiva da sociedade, corre-se o risco da roda girar sobre o próprio eixo. Mobiliza-se, desta maneira, trabalhador e usuários para mudanças circunstanciais ao trabalho, ou às demandas locais, sem se considerar a luta mais ampla de transformação, não só dos serviços como da sociedade?.

Diante das supostas ideias de igualdade frente a um mundo de base desigual cabe lembrar que "Não é a consciência que determina a vida, mas a vida que determina a consciência"33. Não se pode criar uma intencionalidade flutuante de igualdade, pois é a materialidade do capital e a mercantilização das relações sociais que são reais, enquanto a alienação do trabalho e a desigualdade se impõem como referência na realidade.

Não se pode negar, entretanto, que, em seu componente contraditório, as rodas podem constituir mecanismos contra hegemônicos e servir como elemento de luta para a emancipação dos trabalhadores.

Na lógica da PNEPS, é na criação de uma nova subjetividade para o trabalho vivo que a problematização pode contribuir para educar os sujeitos para assumir um compromisso ético-político e tornar-se capaz de atuar criticamente nos micro espaços da saúde. Percebe-se também a influência da noção de aprendizagem significativa de Ausubel nos documentos ministeriais, pois a aprendizagem significativa na PNEPS refere-se a uma pedagogia que concebe um papel mais ativo do aluno/trabalhador, que precisa ter disposição para aprender, pois confronta-se com a tradição da memorização do conteúdo como acontece nos modelos tradicionais ou da educação continuada.

Para que a aprendizagem seja significativa, há que se trabalhar com uma pedagogia diferenciada, que considere cada aprendiz com seus potenciais e dificuldades e que esteja voltada à construção de sentidos, abrindo, assim, caminhos para a transformação e não para a reprodução acrítica da realidade social ${ }^{16}$. 
Ramos $^{39}$ considera que, para além da problematização e da relação dialógica, típicas do pensamento de Paulo Freire e da perspectiva cognitivista de David Ausubel, a teoria da aprendizagem significativa tem influências de Dewey, que valoriza a investigação e reflexão da experiência cotidiana e considera que o pensamento surge de uma situação vivida. Deste modo, a aprendizagem significativa vincula-se ao pragmatismo.

Ao dar destaque à problematização e à aprendizagem significativa, com desvalorização do ensino de repasse de ideias, a PNEPS enaltece o lema aprender a aprender que se incorpora à dinâmica da micropolítica do trabalho, valorizando as tecnologias leves. O lema aprender a aprender carrega em si a ideia de uma autonomia, que daria ao aprendiz a possibilidade de aprendizagem ao longo da vida ${ }^{13}$.

Assim, a SGTES assume a um embate direto com a educação continuada, que é considerada uma pedagogia tradicional, que não produz sujeitos pensantes. Segundo Ceccim ${ }^{20}$ :

Das atividades de educação permanente, das problematizações ao pensar-agir-perceber e de sua interpretação emerge como aprendizagem significativa a invenção de si, nesse processo há a "dissolução de identidades" e a reconfiguração de novas subjetividades. Aquele que aprende é pressionado pelas problematizações a reinventar-se, aos seus coletivos e às suas instituições.

Há uma ênfase na construção de um saber que contribua para gestão do trabalho e colabore para a resolutividade dos serviços. Ramos ${ }^{39}$ considera haver uma aproximação da PNEPS com as teorias sobre organização qualificante, que se desenvolvem sob o preceito de que toda produção atualmente tende a assumir a lógica dos serviços, que se pauta pela imprevisibilidade como origem e ocasião de aprendizagem, adaptabilidade do conhecimento perante as situações mutantes, relevância da comunicação.

Mas é crucial a compreensão de que os problemas do mundo do trabalho que se propõe resolver não são de natureza exclusivamente pedagógica e prática. Percebe-se que ao invés dos ideais de transformação do trabalho do SUS, o que se desencadeia é uma visão de educação pragmatista na qual só o saber aplicável aos serviços tem validade. Educação e gerenciamento permanente do trabalho passam a ser confundir.

Manacorda considera que embora as metodologias novas incontestavelmente produzem uma ruptura, também se limitam pois "põem o homem frente a si mesmo e não diretamente frente ao mundo concreto das coisas e das rela- ções sociais, substitui um processo educativo heterônomo" por um processo "autônomo" que é igualmente limitado ${ }^{40}$.

Duarte $^{41}$ e Miranda ${ }^{42}$ têm considerado que o lema aprender a aprender não é tão "novo", e as propostas construtivistas disseminadas atualmente nada mais são que a velha teoria escolanovista revestida com novas roupagens, assumindo uma "retórica reformista". Porque a roupagem nova? As demandas do chamado capitalismo flexível, implicam novas formas de exploração do trabalho e faz severas críticas à educação descontextualizada desenvolvida pela escola, concebendo que os aprendizes devem educar-se na própria realidade do trabalho.

Nesse sentido, salientamos que a EPS não diz respeito somente a uma questão metodológica na qual os problemas do serviço viriam à tona para resolvê-los. A crítica se faz ao reducionismo, a valorização do saber aplicável aos serviços. Para além deste pragmatismo, torna-se crucial delinear os conteúdos que ampliem a visão dos trabalhadores, emitindo uma melhor compreensão do trabalho e de suas contradições nesta particularidade histórica. Segundo Ramos:

essas contradições só podem ser enfrentadas se concebermos os trabalhadores como sujeitos de conhecimento e de cultura e, com isto, compreendermos qual o sentido dos conhecimentos para os trabalhadores, no exercício profissional em saúde e na sua condição de sujeito que produz sua existência nas relações sociais em geral, num dado tempo histórico. Sendo assim, os desafios da formação de trabalhadores em saúde situam-se também num plano epistemológico, especialmente quanto aos sentidos dos saberes formais ou conhecimentos científicos e dos saberes profissionais técnicos e sociopoliticos, expressos pela histórica e difícil relação entre teoria e prática ${ }^{39}$.

\section{Considerações finais}

É indiscutível a importância da PNEPS que trouxe à tona as discussões sobre a educação e o despertar ético-político dos sujeitos para a consolidação do SUS. No entanto, este estudo demonstra que os fundamentos da PNEPS enfrentam em seu cerne diversos limites ao dar grande peso ao sujeito/trabalhador como elemento de mudança, desconsiderando as condições estruturais que tem grande impacto na qualidade do SUS. Mesmo com a criação do Departamento de Gestão e da Regulação do Trabalho em Saúde (DEGERTS) em 2003 que tem como objetivo atuar em me- 
lhores condições de trabalho no SUS percebe-se que a precarização tem se ampliado desde então. Destacando recentemente, nos primeiros meses de 2015, a aprovação do Projeto de Lei (PL) 4.330 na Câmara dos Deputados, ainda tramitando no Senado Federal que "dispõe sobre os contratos de terceirização e as relações de trabalho deles decorrentes ${ }^{43} \mathrm{e}$ a validação pelo Supremo Tribunal Superior da prestação de serviços públicos não exclusivos por organizações sociais em parceria com o poder público ${ }^{44}$.

À guisa de conclusão é possível constatar que é justamente no momento em que o trabalho se encontra cada vez mais instável e precarizado que o Ministério da Saúde aposta na gestão inovadora, dando centralidade à questão da EPS. Por meio da descentralização da gestão da EPS, rodas são estimuladas a pensar permanentemente em soluções criativas para a superação da ineficiência dos serviços baseados na gestão do trabalho. Considera-se assim que a micropolítica do trabalho vivo, as rodas de gestão e os referenciais da problematização vem colaborar para ideia do gerenciamento permanente.

Como formar um sujeito comprometido a gerir problemas da realidade do trabalho frente às dificuldades estruturais do SUS? Se, por um lado, apontamos a impossibilidade da educação para alterar os limites estruturais do capital, por outro, consideramos que a educação é crucial para a construção de uma nova ordem que busque alterar a realidade da alienação humana. Neste estudo defende-se que contrariamente a uma educação para o cotidiano e pragmatista, cumpre apostar numa educação que favoreça a articulação dos princípios epistemológicos, científicos, estéticos e tecnológicos para além da lógica da sociedade atual e capaz de potencializar rupturas com os mecanismos de exploração vigentes.

Neste sentido essa educação intelectualmente ampliada faz sintonia, muitas vezes com a transmissão de conteúdos/conhecimentos elaborados com base na real história do homem em relações de reciprocidade com outros, que tenham orientação universal, desvelando a opacidade do real e abrindo os horizontes culturais/humanitários dos trabalhadores. Não consideremos apenas os métodos ditos problematizadores como possiblidade de uma formação diferenciada.

Deste modo devemos resgatar uma EPS que de fato articule a "utopia" da "saúde como direito de todos", como possibilidade de qualidade de vida, para usuários e trabalhadores, que em tempos do fortalecimento do neoliberalismo no país se faz extremamente necessária. A luta deve se dar não apenas no cotidiano, mas nos espaços políticos, nas articulações coletivas que fortaleçam o movimento da reforma sanitária e a concretização do SUS constitucional. 


\section{Referências}

1. Gadotti M. Educação e poder: introdução à pedagogia do conflito. 8a ed. São Paulo: Cortez; 1988.

2. Schultz TW. O valor econômico da educação. Rio de Janeiro. Editora: Zahar; 1985.

3. Paiva V. Educação permanente: ideologia educativa ou necessidade social? In: Paiva V, Rattner H, organizadores. Educação Permanente e capitalismo tardio. São Paulo: Cortez; 1985. p. 67-97.

4. Rovere M. Gestion estratégica de la educacion permanente en salud. In: Haddad J, Roschke MALC, Davini MC, organizadores. Educación Permanente de Personal de Salud. Washington: Organizacion Panamericana de la Salud; 1994. Série Desarrollo de Recursos Humanos $n^{\circ} 100$. p. 63-106.

5. Organização Panamericana de Saúde (OPAS). Educación permanente de personal de salud en la región de las américas. Washington: OPAS; 1988. Fascículo I: Propuesta de reorientación. Fundamentos. Serie de desarrrolo de recursos humanos, no 78.

6. Marin AJ. Educação continuada: introdução a uma análise de termos e concepções. In: Collares CAL, Moysés MAA, organizadores. Educação Continuada. Brasília: Cadernos CEDES; 1995.

7. Haddad J, Roschke MALC, Davini MC. Educación Permanente de Personal de Salud. Washington: Organizacion Panamericana de la Salud; 1994. Série Desarrollo de Recursos Humanos no 100 .

8. Ramos MN. Trabalho, educação e correntes pedagógicas no Brasil: um estudo a partir da formação dos trabalhadores técnicos da saúde. Rio de Janeiro: EPSJV, UFRJ; 2010.

9. Vieira M, Durão AVR, Barreto CMG, Carvalho VF Análise da política nacional de educação permanente em saúde: um estudo exploratório dos projetos aprovados pelo Ministério da Saúde, Relatório Final. Rio de Janeiro: Fiocruz; 2006.

10. Lemos CLS. A concepção de educação da política nacional de educação permanente em saúde [tese]. Goiânia: Universidade Federal de Goiás; 2010.

11. Quintana PB, Roschke MAC, Ribeiro ECO. Educación Permanente, processo de trabajo y calidad de servicio en salud. In: Haddad J, Roschke MALC, Davini MC, organizadores. Educación Permanente de Personal de Salud. Washington: Organizacion Panamericana de la Salud; 1994. Série Desarrollo de Recursos Humanos $n^{\circ} 100$. p. 34-60.

12. Brasil. Constituição da República Federativa do Brasil de 1988. Diário Oficial da União 1988; 5 out.

13. Lima JCF, Braga IF. Projeto Memória da Educação Profissional em saúde. Anos1980-1990. Relatório final. Rio de Janeiro: Fiocruz; 2006.

14. Brasil. Portaria no $198 / \mathrm{GM} / \mathrm{MS}$, de 13 de fevereiro de 2004. Institui a Política Nacional de Educação Permanente em Saúde como estratégia do Sistema Único de Saúde para a formação e o desenvolvimento de trabalhadores para o setor e dá outras providências. Diário Oficial da União 2004; 14 fev.

15. Brasil. Portaria GM/MS no 1.996 , de 20 de agosto de 2007. Diretrizes para a implementação da Política Nacional de Educação Permanente. Diário Oficial da União 2007; 21 ago.
16. Brasil. Ministério da Saúde (MS). Secretaria de Gestão do Trabalho e da Educação na Saúde. Departamento de Gestão da Educação em Saúde. Caminhos para a mudança da formação e desenvolvimento dos profissionais de saúde: diretrizes para a ação política para assegurar Educação Permanente no SUS. Brasília: MS; 2003

17. Brasil. Ministério da Saúde (MS). Secretaria de Gestão do Trabalho e da Educação na Saúde. Departamento de Gestão da Educação em Saúde. Curso de Formação dos Facilitadores de Educação Permanente em saúde. Gestão do trabalho e da regulação profissional em saúde: agenda positiva. Brasília: MS; 2004.

18. Brasil. Ministério da Saúde (MS). Secretaria de Gestão do Trabalho e da Educação na Saúde. Departamento de Gestão da Educação na Saúde. Política de educação e desenvolvimento para o SUS: caminhos para a educação permanente em saúde: pólos de educação permanente em saúde. Brasília: MS; 2004.

19. Brasil. Ministério da Saúde (MS). A Educação Permanente entra na Roda. Pólos de Educação Permanente em Saúde: conceitos e caminhos a percorrer. Brasília: MS; 2005. Serie C. Projetos, Programas e Relatórios.

20. Ceccim RB. Educação permanente em saúde: desafio ambicioso e necessário. Interface (Botucatu) 2004/2005. 9(16):161-177.

21. Ceccim RB. Educação permanente em saúde: descentralização e disseminação de capacidade pedagógica na saúde. Cien Saude Colet 2005; 10(4):975-986.

22. Merhy E. O desafio que a educação permanente tem em si: a pedagogia da implicação. Interface (Botucatu) 2005; 9(16):172-174.

23. Ceccim RB, Feurwerker CMF. O quadrilátero da formação para a área da saúde: ensino, gestão, atenção e controle Social. Physis: Rev. Saúde Coletiva 2004; 14(1):41-65.

24. Merhy EE, Feuerwerker LCM, Ceccim RB. Educación permanente en salud: una estrategia para intervenir en la micropolítica del trabajo en salud. Salud colectiva 2006; 2(2):147-160.

25. Barbosa RHS. A teoria da práxis: retomando o referencial marxista para o enfrentamento do capitalismo no campo da saúde. Trab. Educ. Saúde 2010; 8(1):9-26.

26. Bravin FP. Política e ação pública: análise da Política Nacional de Educação Permanente em Saúde [dissertação]. Brasília: Universidade de Brasília; 2008.

27. Marx K. Manuscritos econômico-filosóficos. São Paulo: Boitempo; 2004.

28. Guatarri F, Rolnik S. Micropolítica: cartografias do desejo. Petrópolis: Editora Vozes; 1986.

29. Marx K. O capital: crítica da economia política. São Paulo: Abril Cultural; 1983.

30. Merhy EE. Saúde: a cartografia do trabalho vivo. São Paulo: Hucitec; 2002.

31. Lukács G. Ontologia do Ser Social: os princípios ontológicos fundamentais de Marx. São Paulo: Livraria e Editora Ciências Humanas; 1979.

32. Mészaros I. Para além do capital. São Paulo: Boitempo; 2002.

33. Marx K, Engels F. A ideologia alemã. São Paulo: Martin Claret; 2005 
34. Garrafa V, Cordón J. Determinantes sociais da doença. Saúde em Debate.2009; 33(83):388-396.

35. Kuenzer AZ. Sob a reestruturação produtiva, enfermeiros, professores e montadores de automóveis se encontram no sofrimento do trabalho. Trabalho, Educação e Saúde 2004; 2(1):239-265.

36. Franco TB. As redes na micropolítica do processo de trabalho em saúde. In: Pinheiro R, Matos RA, organizadores. Gestão em redes. Rio de Janeiro: Lappis, IMS/ UERJ, Abrasco; 2006. p. 459-474.

37. Campos GWS. Efeito Paidéia e o campo da saúde: reflexões sobre a relação entre o sujeito e o mundo da vida. Trabalho, Educação e Saúde 2006; 4(1):19-31.

38. Campos GWS. Clínica e saúde coletiva compartilhadas: teoria paidéia e reformulação ampliada do trabalho em saúde. In: Campos GW, Minayo MC, Akerman M, Drumond Júnior M, Carvalho YM, organizadores. Tratado de saúde coletiva. São Paulo: Hucitec; 2006. p. 53-92.

39. Ramos MN. Referência teórico-metodológicas da educação permanente em saúde no Brasil. Rio de Janeiro: Fiocruz; 2006. Mimeografado.

40. Manacorda MA. Marx e a pedagogia moderna. São Paulo, Campinas: Cortez, Autores Associados; 1991.

41. Duarte N. Vigotsky e o "aprender a aprender": crítica às apropriações neoliberais e pós-modernas da teoria vigotskiana. 2a ed. Campinas: Autores Associados; 2001. (Coleção Educação Contemporânea).

42. Miranda GM. O novo paradigma do conhecimento e políticas educacionais na América Latina. Cadernos de Pesquisa 1997; 100:37-48.

43. Supremo Tribunal Federal (STF). Notícias do STF. Convênio do poder público com organizações sociais deve seguir critérios objetivos. 2015. [acessado 2015 maio 12]. Disponível em: http://www.stf.jus.br/portal/ $\mathrm{cms} /$ verNoticiaDetalhe.asp?idConteudo $=289678$

44. Câmara dos Deputados. PL 4330/2004.2015. [acessado 2015 maio 12]. Disponível em: http://www.camara. gov.br/proposicoesWeb/fichadetramitacao?idProposi$\mathrm{cao}=267841$

Artigo apresentado em 11/09/2014

Aprovado em 11/07/2015

Versão final apresentada em 13/07/2015 